
and Biochemistry

\title{
EMT Phenotype is Induced by Increased Src Kinase Activity via Src-Mediated Caspase-8 Phosphorylation
}

Yang Zhao ${ }^{1}$, XiaoJun $\mathrm{Li}^{1}$, XiangFei Sun ${ }^{1}$, YunFeng Zhang ${ }^{1}$ and Hong Ren ${ }^{1}$

${ }^{1}$ Department of Oncosurgery, First Affiliated Hospital of Medical College of Xi'an Jiao Tong University, Xi'an, Shaanxi Province

\section{Retracted Statement See Next Page}




\section{Retraction Statement}

Paper by Zhao Y, Li X, Sun X, Zhang Y, Ren H, entitled 'EMT phenotype is induced by increased Src kinase activity via Src-mediated caspase-8 phosphorylation' [Cell Physiol Biochem 2012;29 (3-4):341-352, DOI: 10.1159/000338489]

The Editor and Publisher of Cellular Physiology and Biochemistry wish to state that the following article has been retracted from the Journal due to fabrication. 